\title{
Emerging Opportunities for c-MET Visualization in the Clinic
}

\author{
Martin Pool ${ }^{1}$, Gooitzen M. van Dam ${ }^{2}$, and Elisabeth G.E. de Vries ${ }^{1}$ \\ ${ }^{1}$ Department of Medical Oncology, University Medical Center Groningen and University of Groningen, Groningen, The Netherlands; \\ and ${ }^{2}$ Departments of Surgery \& Nuclear Medicine and Molecular Imaging, University Medical Center Groningen and University of \\ Groningen, Groningen, The Netherlands
}

$\mathbf{I}$ this issue of The Journal of Nuclear Medicine, Arulappu et al. present results of c-MET-specific peptide ${ }^{18} \mathrm{~F}$-AH113804 PET screening for local regional recurrence after surgical excision of orthotopically implanted HCC1954 human basal-like breast cancer (BLBC) xenografts. ${ }^{18} \mathrm{~F}$-AH113804 PET could visualize this locoregional recurrence as early as $6 \mathrm{~d}$ postoperatively, whereas CT did so after day 20 , and tumors were first palpable only by day 27 . They were also able to differentiate between high and low c-MET-expressing tumors. On the basis of these results, the authors concluded that ${ }^{18} \mathrm{~F}-\mathrm{AH} 113804 \mathrm{c}-\mathrm{MET}$ PET has potential as a clinical screening tool for earlier detection of locoregional BLBC recurrences (1).

c-MET is an interesting target for molecular imaging and treatment in solid tumors. It is a tyrosine growth factor receptor and together with ligand hepatocyte growth factor (HGF), c-MET is often dysregulated in cancers, including breast cancer. Increased activation of the c-MET/HGF pathway leads to invasion, angiogenesis, motility, and cell proliferation (2).

\section{See page 765}

Breast cancers are subdivided in molecular subtypes. One of these is triple-negative breast cancer (TNBC), which is characterized by lack of human epidermal growth factor receptor 2 (HER2) and estrogen and progesterone receptor overexpression. BLBC, which served as a model for Arulappu et al. (1), expresses gene characteristics for normal basal or myoepithelial breast cells. BLBCs comprise around $80 \%$ of TNBCs, and $80 \%$ of BLBCs are classified as a TNBC. Although not completely overlapping, BLBC is often used interchangeably with the term TNBC $(3,4)$. About 15\%-20\% of all breast cancer patients have TNBC (5). Locoregional relapses develop in $12 \%-14 \%$ of these patients, and the overall recurrence rate is $35 \%-40 \%$ within 5 y $(6,7)$.

After primary breast cancer treatment, current guidelines advise regular physical examinations approximately every 3-12 mo and yearly mammography for the first $5 \mathrm{y}$. In the absence of clinical signs and symptoms suggestive of recurrent disease, no laboratory

\footnotetext{
Received Dec. 21, 2015; revision accepted Dec. 22, 2015.

For correspondence or reprints contact: Elisabeth GE de Vries, Department of Medical Oncology, University Medical Center Groningen and University of Groningen, Groningen, The Netherlands.

E-mail: e.g.e.de.vries@umcg.nl

Published online Jan. 28, 2016.

COPYRIGHT (c) 2016 by the Society of Nuclear Medicine and Molecular Imaging, Inc.

DOI: $10.2967 /$ jnumed.115.169771
}

or imaging studies for metastases screening are advised (8-10). Most locoregional recurrences present themselves by clinical signs and symptoms such as lumps, swelling, or inflamed skin, whereas mammography and physical examination detect most other locoregional recurrences (11).

Although screening for locoregional recurrences using PET seems enticing, this reasoning incurs potential pitfalls. In contrast to the preclinical model in which local recurrences were already present $6 \mathrm{~d}$ after surgery, recurrences in TNBCs peak between 1-2 y after surgery (6). Therefore, follow-up of these patients would likely encompass numerous, costly, PET scans during the first $5 \mathrm{y}$ next to the advised yearly mammographies. Moreover, the inherent spatial resolution of whole-body PET scans is currently around 10-15 mm, whereas locoregional recurrences this size are likely to be detected by palpation or conventional mammography. When whole-body PET scanning is performed, distant metastases may also be visualized. Modern PET/CT cameras and dedicated positron emission mammography could improve the spatial resolution of PET tracers (12), with the dedicated positron emission mammography at a loss of whole-body detection capability for possible distant metastases. Risk associated with radiation exposure induced by PET scans would have to be justified by potential outcome benefits. For instance, a single ${ }^{18}$ F-FDG PET scan incurs around 3.99 (European Association of Nuclear Medicine Research Ltd. guidelines) to 6.2$7.1 \mathrm{mSv}$ (13). The $60 \%-65 \%$ of TNBC patients who will not relapse would receive additional radiation exposure if routinely screened by c-MET PET, next to the approximately $0.4 \mathrm{mSv}$ dose per annual mammography (13). The patient population that might be considered for c-MET PET imaging could possibly be initially enriched by selecting for known local recurrence risk factors such as primary tumor size, vascular invasion, and node positivity (14). However, a follow-up protocol of patients using a 1-target approach is likely to result in a significant number of false-negative results. This is mainly due to the lack of expression of the c-MET receptor in about half of the TNBC patients (5). However, a selection for c-MET imaging based on expression in primary tumors might underestimate the c-MET expression, because conversion from lowexpressing primary tumors to high c-MET levels in recurrent lesions has been observed (15). It will, however, be difficult for c-MET to compete with more general tumor characteristics such as elevated glucose consumption reflected by ${ }^{18} \mathrm{~F}-\mathrm{FDG}$ PET imaging, because ${ }^{18} \mathrm{~F}-\mathrm{FDG}$ performs relatively well in TNBC (16). Given these arguments, we do not at this moment foresee a routine place for the ${ }^{18} \mathrm{~F}-\mathrm{AH} 113804$ PET tracer for broad local recurrence screening. However, there may well be other future reasons to target c-MET for imaging. 
There are several other successfully tested preclinical c-MET PET tracers, including ${ }^{64} \mathrm{Cu}$-labeled HGF (17), ${ }^{89} \mathrm{Zr}$-labeled anticalin PRS-110 (18), ${ }^{124} \mathrm{I}$ - and ${ }^{89} \mathrm{Zr}$-labeled full-length murine antibody DN30 (19), 1-armed antibody ${ }^{89} \mathrm{Zr}$-onartuzumab (20), and a ${ }^{89} \mathrm{Zr}$-labeled $\mathrm{H} 2$ cys-diabody and $\mathrm{H} 2$ minibody (21). They have different properties, such as binding site, residualizing radiometals for improved contrast and varying tumor targeting kinetics, and clearance rates. Some strategies involve labeling of existing drug candidates as proxy for drug tumor deposition, whereas others involve specially generated c-MET-targeting proteins.

Next to c-MET imaging with a PET tracer, imaging with a fluorescent tracer might be of interest. Recently, GE-137, a fluorescent c-MET probe of which the targeting moiety is based on the same peptide used by Arulappu et al., was successfully applied to detect polyps in individuals at risk for colorectal cancer. These individuals underwent regular screening colonoscopies and GE-137 served as an add-on red-flag fluorescent imaging technique (22). Benefits of this strategy compared with radionuclidebased imaging are a less costly infrastructure and availability of off the shelf nonradioactive tracers. It is especially of interest when information of a limited body area is needed because no whole-body information can be obtained. In the future, potentially multiple fluorescent tracers with different distinct wavelengths targeting several targets could be used simultaneously in a multiplexed imaging setting to gain even more insight. Fluorescence imaging of growth factor receptors/ligands in the breast is currently actively pursued in the intraoperative setting, with the ultimate goal to obtain superior information concerning tumor-free margins. Moreover, recent developments in multispectral optoacoustic imaging allows for noninvasive real-time imaging using a hand-held probe in the outpatient clinic. This strategy combines superior resolution with high signal penetration for visualization of tissues. It might therefore be a tool for local breast recurrence screening purposes without radiation burden (23), whereas a c-MET fluorescent tracer could be part of the multispectral optoacoustic imaging screening with a tracer cocktail against oftenexpressed breast cancer targets.

TNBCs are characterized by a generally poor prognosis compared with other breast cancer subtypes as well as a lack of targeted treatment options (24). This has stimulated the search for drugable targets for this particular subgroup. It is of interest that several c-MET-targeted therapeutics are currently evaluated in breast cancer trials, such as the small-molecule tyrosine kinase inhibitors tivantinib, cabozantinib and foretinib, 1-armed c-MET antibody onartuzumab, and autologous cMET-redirected T cells. Preliminary clinical efficacy of such compounds in TNBC is modest (5). Pretreatment c-MET PET scans as a noninvasive accompanying biomarker could potentially enrich the patient population that might benefit from c-MET/HGF-targeted drugs (25), by providing insight in whole-body c-MET target distribution. When imaging c-MET obtains a role in the clinic, the answers required for patients will ultimately guide selection of the imaging modality and optimal tracer.

\section{DISCLOSURE}

This work was supported by ERC grant OnQview and Dutch Cancer Society grant IMPACT RUG 2012-5565. Genentech and Pieris research grants to Elisabeth GE Vries were made available to the UMCG. Gooitzen M. van Dam received an unrestricted research grant from SurgVision. No other potential conflict of interest relevant to this article was reported.

\section{REFERENCES}

1. Arulappu A, Battle M, Eisenblaetter M, et al. c-Met PET imaging detects earlystage locoregional recurrence of basal-like breast cancer. J Nucl Med. 2016;57: 765-770.

2. Blumenschein GR, Mills GB, Gonzalez-Angulo AM. Targeting the hepatocyte growth factor-cMET axis in cancer therapy. J Clin Oncol. 2012;30:3287-3296.

3. Prat A, Adamo B, Cheang MCU, Anders CK, Carey LA, Perou CM. Molecular characterization of basal-like and non-basal-like triple-negative breast cancer. Oncologist. 2013;18:123-133.

4. Foulkes WD, Smith IE, Reis-Filho JS. Triple-negative breast cancer. $N$ Engl J Med. 2010;363:1938-1948.

5. Minuti G, Landi L. MET deregulation in breast cancer. Ann Transl Med. 2015;3:181.

6. Pogoda K, Niwińska A, Murawska M, Pieńkowski T. Analysis of pattern, time and risk factors influencing recurrence in triple-negative breast cancer patients. Med Oncol. 2013;30:388.

7. Dent R, Trudeau M, Pritchard KI, et al. Triple-negative breast cancer: clinical features and patterns of recurrence. Clin Cancer Res. 2007;13:4429-4434.

8. National Comprehensive Cancer Network (NCCN). NCCN website. http://www.ncen. org/professionals/physician_gls/pdf/breast-screening.pdf. Accessed March 17, 2016.

9. Khatcheressian JL, Hurley P, Bantug E, et al. Breast cancer follow-up and management after primary treatment: American Society of Clinical Oncology clinical practice guideline update. J Clin Oncol. 2013;31:961-965.

10. Senkus E, Kyriakides S, Ohno S, et al. Primary breast cancer: ESMO clinical practice guidelines for diagnosis, treatment and follow-up. Ann Oncol. 2015;26(suppl 5):v8-v30.

11. Geurts SME, de Vegt F, Siesling S, et al. Pattern of follow-up care and early relapse detection in breast cancer patients. Breast Cancer Res Treat. 2012;136: 859-868.

12. MacDonald L, Edwards J, Lewellen T, Haseley D, Rogers J, Kinahan P. Clinical imaging characteristics of the positron emission mammography camera: PEM Flex Solo II. J Nucl Med. 2009;50:1666-1675.

13. Hendrick RE. Radiation doses and cancer risks from breast imaging studies. Radiology. 2010;257:246-253.

14. Wallgren A, Bonetti M, Gelber RD, et al. Risk factors for locoregional recurrence among breast cancer patients: results from international breast cancer study group trials I through VII. J Clin Oncol. 2003;21:1205-1213.

15. Camp RL, Rimm EB, Rimm DL. Met expression is associated with poor outcome in patients with axillary lymph node negative breast carcinoma. Cancer. 1999;86:2259-2265.

16. Basu S, Chen W, Tchou J, et al. Comparison of triple-negative and estrogen receptor-positive/progesterone receptor-positive/HER2-negative breast carcinoma using quantitative fluorine-18 fluorodeoxyglucose/positron emission tomography imaging parameters. Cancer. 2008;112:995-1000.

17. Luo $\mathrm{H}$, Hong $\mathrm{H}$, Slater MR, et al. PET of c-Met in cancer with ${ }^{64} \mathrm{Cu}$-labeled hepatocyte growth factor. J Nucl Med. 2015;56:758-763.

18. Terwisscha van Scheltinga AGT, Lub-de Hooge MN, Hinner MJ, et al. In vivo visualization of MET tumor expression and anticalin biodistribution with the METspecific anticalin ${ }^{89} \mathrm{Zr}$-PRS-110 PET Tracer. $J$ Nucl Med. 2014;55:665-671.

19. Perk LR, Stigter-van Walsum M, Visser GW, et al. Quantitative PET imaging of Met-expressing human cancer xenografts with ${ }^{89} \mathrm{Zr}$-labelled monoclonal antibody DN30. Eur J Nucl Med Mol Imaging. 2008;35:1857-1867.

20. Jagoda EM, Lang L, Bhadrasetty V, et al. Immuno-PET of the hepatocyte growth factor receptor Met using the 1-armed antibody onartuzumab. J Nucl Med. 2012;53:1592-1600.

21. Li K, Tavaré R, Zettlitz KA, et al. Anti-MET immunoPET for non-small cell lung cancer using novel fully human antibody fragments. Mol Cancer Ther. 2014; 13:2607-2617.

22. Burggraaf J, Kamerling IMC, Gordon PB, et al. Detection of colorectal polyps in humans using an intravenously administered fluorescent peptide targeted against c-Met. Nat Med. 2015;21:955-961.

23. Taruttis A, van Dam GM, Ntziachristos V. Mesoscopic and macroscopic optoacoustic imaging of cancer. Cancer Res. 2015;75:1548-1559.

24. Hudis CA, Gianni L. Triple-negative breast cancer: an unmet medical need. Oncologist. 2011;16(suppl 1):1-11.

25. Lamberts LE, Williams SP, Terwisscha van Scheltinga AGT, et al. Antibody positron emission tomography imaging in anticancer drug development. J Clin Oncol. 2015;33:1491-1504. 